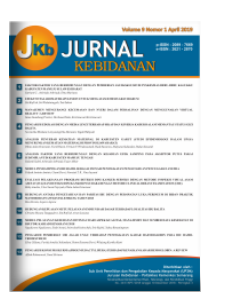

Volume 10 Nomor 1 (2020) 74-79

JURNAL KEBIDANAN

p-ISSN: 2089-7669 ; e-ISSN: 2621-2870

https://doi.org/10.31983/jkb.v10i1.5593

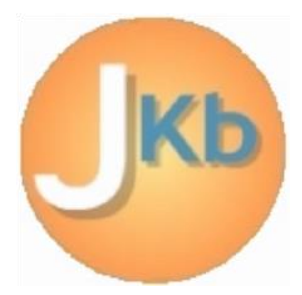

\title{
Cerebral Palsy Types Based on Kind of Disability Correlated with The Functional Independence
}

\author{
Bambang Trisnowiyanto*, Isna Andriani \\ Department of Physiotherapy, Poltekkes Kemenkes Surakarta \\ Jl. Kapt. Adi Soemarmo, Tohudan Colomadu, Karanganyar, Jawa Tengah, Indonesia \\ Corresponding author: Bambang Trisnowiyanto \\ Email: trisnowiyanto@yahoo.co.id \\ Received: February $13^{\text {th }}, 2020$; Revised: April 24 $4^{\text {th }}, 2020$; Accepted: April $30^{\text {th }}, 2020$
}

\begin{abstract}
Cerebral palsy is a collection of motor disorders caused by brain damage that occur before, during or after birth which can be caused by many factors such as, congenital, genetic, inflation, infection and poisoning during pregnancy, trauma and metabolic disorders. Children with cerebral palsy will mostly have problems with posture. Therefore, to find out the level of independence in children with cerebral palsy, it is necessary to have an examination carried out by health workers, especially physiotherapy. The purpose of this study was to determine the prevalence of the most common type of CP that occurred in CP events which were correlated with the level of activities functional independence of the child's movements. This research was an observational descriptive study with a measuring instrument for the Gross Motor Function Classification System Expanded and Resived. Based on the analysis of the data obtained in the independent category of 33 children (6,3\%) with quadriplegia spastic CP type, 34 children $(6,5 \%)$ with diplegia spastic CP type, 15 children $(2,9 \%)$ with spastic hemiplegia CP type , 19 children $(3,6 \%)$ with atetoid CP type, and 28 children $(5,4 \%)$ with hyponia CP type. On the other hands, in the dependent category there were 149 children $(28,5 \%)$ with quadriplegia spastic CP type, 156 children $(29,8 \%)$ with diplegia spastic CP type, 18 children (3,4\%) with spastic hemiplegia CP type, 27 children $(5,2 \%)$ with atetoid CP type, and 44 children $(8,4 \%)$ with hyponia CP type. Conclusion the type of CP that has the highest prevalence was spastic group $\mathrm{CP}$ with a low or dependent level of independence, and correlates perfectly $(+1)$ between the types of cerebral palsy with the level of functional independence of children based on pearson product moment.
\end{abstract}

Keywords: cerebral palsy types; kind of disability; functional independence

\section{Introduction}

Children experience growth and development processes that begin from the womb, infancy, toddler, school age and adolescence, where in the growth and development of children can experience obstacles caused by many factors. The three most common growth and development disorders in children and the most prevalent are cerebral palsy, autism and mental disorders. Children who experience neurological dysfunction can cause weakness and disability with will affect the next life.[1-3]

Copyright @2020, JURNAL KEBIDANAN, http://ejournal.poltekkes-smg.ac.id/ojs/index.php/jurkeb/index
Cerebral Palsy (CP) is the most common motor disability disorder in children with a prevalence of 2-3 per 1000 live births [4]. 50\% of cases are mild, namely the patient can take care of himself, and $10 \%$ is classified as severe, namely the patient requires special services. $35 \%$ are accompanied by seizures and $50 \%$ have speech problems, with an average of $70 \%$ spastic type, 10$20 \%$ atetotic type, $5-10 \%$ ataxia, and the rest are mixed type.[5-6]

The term CP is explained as a group of permanent disorders of the development of motion and posture that cause limitation in activity, which 
occurs due to non progressive disorders in the brain of a developing baby or fetus. Motor disorders in $\mathrm{CP}$ are often accompanied by disorders of sensation, perception, cognition, communication, behavior, epilepsy, and secondary disorders of the musculoskeletal system.[7] Disturbances in CP can be caused by risk factors that occur in the prenatal, perinatal, and postnatal period. [8]

CP topographic classifications are monoplegia, hemiplegia, diplegia and quadriplegia; monoplegia and triplegia are relatively unusual. There is a substantial overlap of the area affected. In most studies, diplegia is the most common form (30\%-40\%), hemiplegia is $20 \%-30 \%$, and quadriplegia accounting for $10 \%-15 \%$. In an analysis of $1000 \mathrm{CP}$ cases from India, it was found that spastic quadriplegia constituted $61 \%$ of cases followed by $22 \%$ diplegia.[9]

Children with $\mathrm{CP}$ will mostly experience problems with posture, so to know the level of independence in children with $\mathrm{CP}$, it is necessary to have an examination carried out by health workers, especially physiotherapy. In this case, an inspection using the Expanded and Resived Gross Motor Function Classification System (GMFCSER) is used. GMFCS-ER is an approach to classify children according to their level of motor ability. GMFCS-ER is presented in five classification classes where the higher the level, the less the ability of children. [10-12].

The formulation of the problems in this study are (1) what type of cerebral palsy is the most based on the type of disability that occurs in cerebral palsy events? (2) how is the independence of functional activities of basic motion in children with cerebral palsy? and (3) is there a relationship between the type of cerebral palsy with the independence of the functional activities of basic motion in children?

The purpose of this study is (1) to find out the type of cerebral palsy that is most based on the type of disability, and (2) to determine the independence of basic functional functional activities in children with cerebral palsy and (3) to determine the relationship between the types of cerebral palsy with independence functional activities of basic motion in children.

The expected benefits of this research are (1) theoretical, a means to enrich and develop knowledge related to cerebral palsy, (2) practical, used as a reference in developing interventions that are appropriate to the disability they experience.

\section{Methods}

This type of research is descriptive research which is a method of examining human status, an object, a situation or condition, system of thought, or a broad range of thoughts in the present. The purpose of this research is to research a group of people, an object, a set of conditions in a system of thought or broad thinking in the present with the aim of describing, describing, or describing systematically, factually, and accurately about facts, traits, and the relationship between the phenomena investigated.

The research conducted in March-June 2019. Treatment in the form of survey data and direct examination of children with cerebral palsy in the parents' community association cerebral palsy.

The subjects were 523 cerebral palsy children from community associations of parents of cerebral palsy children who met the inclusion and exclusion criteria.

Inclusion criteria that must be met were as follows: (1) children with a medical diagnosis of cerebral palsy and (2) age range between 2-18 years

Exclusion criteria (1) cerebral palsy children who are taking part in an intervention program other than physiotherapy, (2) the presence of severe complications that interfere with motor function such as contractures and deformity, respiratory distress, and poor nutritional status.

The drop-out criteria are (1) the subject did not complete the intervention program more than twice or more during the intervention period and (2) was sick, injured, or died so as to stop the exercise program.

The variables in this study are the type of $\mathrm{CP}$ based on the type of disability and the level of independence of basic functional functional activities in children, namely the ability of $\mathrm{CP}$ children to perform functional activities in daily life independently.

$\mathrm{CP}$ is categorized into several types based on the type of disability and topis of the lesion that occurs in a person with CP. CP type consists of spastic $\mathrm{CP}$ type, atetoid $\mathrm{CP}$ type, hypoonia $\mathrm{CP}$ type, ataxia CP type and mixed CP type. Spastic $\mathrm{CP}$ types are divided into 3 types, namely quadriplegia spasticity, spastic diplegia spastic hemiplegia and spastic monoplegia.

The measuring instrument used to determine the level of independence of basic functional functional activities in children with $\mathrm{CP}$ is the Expanded and Resived Gross Motor Function Classification System (GMFCS-ER). GMFCS-ER 
is presented in five classification classes where the higher the level, the less the ability of children. Children with CP who have GMFCS-ER level 1 and 2 are categorized as having a good level of independence. Whereas children with $\mathrm{CP}$ who have GMFCS-ER level 3, 4 and 5 are categorized as having insufficient independence so that in carrying out daily activities and mobility, they need assistive devices and caregiver assistance. CP children with GMFCS-ER levels level 3, 4 and 5 need medical management and health workers in their activities. [12]

Statistical analysis used to test data correlation using Pearson product moment. Pearson product moment correlation is a parametric backfill, will produce a correlation coefficient that serves to measure the strength of a linear relationship between two variables. Perason correlation has a range of values from -1 to +1 . If the correlation coefficient is -1 then the two variables studied have a negative linear relationship. If the correlation coefficient is +1 then the two variables studied have a perfectly positive linear relationship. If the correlation coefficient shows the number 0 , then there is no relationship between the 2 variables studied. Data were analyzed with frequency distribution tables using the SPSS-20 application.

\section{Results and Discussion}

The study was conducted in cerebral palsy communities in Indonesia. The research sample was the total population of cerebral palsy children in all communities that meet the research criteria, namely the age range of 2-18 years, with a total sampling method.

Table 1.

Subject Characteristics Based on Gender

\begin{tabular}{ccc}
\hline Gender & $\begin{array}{c}\text { Total } \\
\text { Subject }\end{array}$ & Presentation \\
\hline Male & 323 & $62 \%$ \\
Female & 200 & $38 \%$ \\
\hline
\end{tabular}

Source: Primary Data, 2019

Table 2.

Subject Characteristics Based on Age

\begin{tabular}{ccc}
\hline Age & Total Subject & Presentation \\
\hline$<2$ years & 59 & $11 \%$ \\
2-5 years & 173 & $33 \%$ \\
6-12 years & 177 & $34 \%$ \\
13-18 years & 114 & $22 \%$ \\
\hline
\end{tabular}

Source: Primary Data, 2019
Table 3.

Type Of Cerebral Palsy

\begin{tabular}{ccc}
\hline $\begin{array}{c}\text { Cerebral Palsy } \\
\text { Types }\end{array}$ & $\begin{array}{c}\text { Total } \\
\text { Subject }\end{array}$ & Presentation \\
\hline Spastic & & \\
Quadriplegia & 182 & $35 \%$ \\
Spastic Diplegia & 190 & $36 \%$ \\
Spastic & 33 & $6 \%$ \\
Hemiplegia & 46 & $9 \%$ \\
Atetoid & 72 & $14 \%$ \\
Hypotonia & - & $0 \%$ \\
Ataxia & - & $0 \%$ \\
Mix & & \\
\hline
\end{tabular}

Source: Primary Data, 2019

Table 4.

Level of Independence of Functional Activities of Basic Movement in Children with Cerebral Palsy

\begin{tabular}{ccc}
\hline GMFCS-ER & $\begin{array}{c}\text { Total } \\
\text { Subject }\end{array}$ & Presentation \\
\hline Level I & 64 & $12,2 \%$ \\
Level II & 65 & $12,4 \%$ \\
Level III & 125 & $23,9 \%$ \\
Level IV & 161 & $30,8 \%$ \\
Level V & 108 & $20,7 \%$ \\
\hline
\end{tabular}

Source: Primary Data, 2019

The total subjects were 523 children (100\%), $323(62 \%)$ children were male and $200(38 \%)$ children were female.

The total subjects were 523 children $(100 \%)$, 59 children $(11 \%)$ aged <2 years, 173 children (33\%) aged 2-5 years, 177 children (34\%) aged 612 years and 114 children (22\% ) 13-18 years old.

The most types of $\mathrm{CP}$ obtained from research data at the Kitty Center Clinic in Jakarta are the spastic CP groups, which are 182 quadriplegia spastic children (35\%), 190 diplegia spastic children (36\%), 33 hemiplegia spastic children (6\%), then atetoid CP type 46 children (9\%), 72 types of hyponia $\mathrm{CP}(14 \%)$, and no ataxia type and mixed $\mathrm{CP}$ types $(0 \%)$ were found.

The level of independence of basic functional functional activities in children with $\mathrm{CP}$ at the Kitty Center Clinic in Jakarta based on examination with GMFCS-ER obtained 64 data children (12.2\%) level I category, 65 children (12.4\%) level II category, 125 children ( 23.9\%) level III category, 161 children (30.8\%) level IV category and 108 children (20.7\%) level V. category. Children with CP who have GMFCS-ER level 1 and 2 are categorized as having a good level of independence. Whereas children with $\mathrm{CP}$ who have GMFCS-ER level 3, 4 and 5 are categorized as having insufficient independence so that in carrying out daily activities and mobility. 
Table 5.

Type of Cerebral Palsy with Children's Functional Independence

\begin{tabular}{ccccc}
\hline \multirow{2}{*}{ Cerebral Palsy Types } & \multicolumn{2}{c}{ Independent Category } & \multicolumn{2}{c}{ Dependent Category } \\
\cline { 2 - 5 } & Total Subject & Presentation & Total Subject & Presentation \\
\hline Spastic Quadriplegia & 33 & $6,3 \%$ & 149 & $28,5 \%$ \\
Spastic Diplegia & 34 & $6,5 \%$ & 156 & $29,8 \%$ \\
Spastic Hemiplegia & 15 & $2,9 \%$ & 18 & $3,4 \%$ \\
Atetoid & 19 & $3,6 \%$ & 27 & $5,2 \%$ \\
Hypotonia & 28 & $5,4 \%$ & 44 & $8,4 \%$ \\
Ataxia & - & $0 \%$ & - & $0 \%$ \\
Mix & - & $0 \%$ & - & $0 \%$ \\
\hline
\end{tabular}

Source: Primary Data, 2019

Table 6.

Correlation of Cerebral Palsy Type with Children's Functional Independence Based on Pearson Product Moment

\begin{tabular}{cccc}
\hline & & CP Types & Indepen-dence \\
\hline CP Types & Pearson Correlation & 1 & $-.208^{* * *}$ \\
& Sig. (2-tailed) & & .000 \\
Indepen-dence & Pearson Correlation & 523 & 523 \\
& Sig. (2-tailed) & $-.208^{* * *}$ & 1 \\
& $\mathrm{~N}$ & .000 & 523 \\
\hline
\end{tabular}

**. Significant correlation at the 0.01 level (2-tailed).

The type of $\mathrm{CP}$ with independence of basic functional functional activities in children was 129 amount $(24.7 \%)$ with independent category and dependent category was 394 children $(75.3 \%)$. In the independent category there were 33 children (6.3\%) with quadriplegia spastic $\mathrm{CP}$ type, 34 children (6.5\%) with diplegia spastic CP type, 15 children $(2.9 \%)$ with hemiplegia spastic CP type, 19 children $(3,6 \%)$ with atetoid CP type, and 28 children $(5.4 \%)$ with hyponia CP type. In the dependent category there were 149 children (28.5\%) with quadriplegia spastic CP type, 156 children (29.8\%) with diplegia spastic CP type, 18 children (3.4\%) with hemiplegia spastic CP type, 27 children $(5,2 \%)$ with atetoid CP type, and 44 children (8.4\%) with hyponia CP type.

From the results of statistical data analysis using pearson product moment correlation scale obtained positive positive correlation $(+1)$ between the type of $\mathrm{CP}$ with the independence of functional activity of basic motion in children.

The most types of $\mathrm{CP}$ obtained from research data are 405 children $(77.4 \%)$ of spastic $\mathrm{CP}$, then 46 children of atetoid CP (9\%), 72 children (14\%) of hypotonic CP CP ataxia and mixed CP types (0\%) were found. The most common disability $\mathrm{CP}$ groups based on disability were 190 children (36\%) diplegia, 182 quadriplegia children (35\%), and 33 children (6\%) spastic hemiplegia.

This study is in line with the literature review conducted by Odding et al. (2006) obtained epidemiological data based on the type of $\mathrm{CP}$, the most types are the spastic group, which is between $72-91 \%$, while the non-spastic group is $9-28 \%$.

The level of independence of basic functional functional activities in children with $\mathrm{CP}$ based on examination with GMFCS-ER obtained results at level I and II totaling 129 children (24.7\%) in the independent category and at levels III, IV and V totaling 394 children (75.3\%) in the dependent category. It was concluded that the majority of children with $\mathrm{CP}$ had low or dependent levels of independence.

Research conducted by Beckung et al. (2008) in Europe also obtained results of $50 \%$ of cases of CP including severe while $10 \%$ included mild. Understanding mild motor deficits are sufferers who can take care of themselves, while those classified as severe motor deficits are sufferers who cannot take care of themselves or are dependent.

Based on the results of the study of the correlation between the type of $\mathrm{CP}$ on the level of functional independence of children with $\mathrm{CP}$ with Pearson product moment obtained a perfectly positive correlation $(+1)$. 
Although $\mathrm{CP}$ is a disorder that is not progressive, but its clinical expression can change along with the process of brain maturation. The symptoms of $\mathrm{CP}$ and their severity are different, depending on the part of the brain that is damaged, and may even change in one individual over time. Most CP children have at least one comorbid or comorbid disorder. [4]

Motor disorders in $\mathrm{CP}$ children are often accompanied by impaired sensation, perception, cognition, communication and behavior, epilepsy, and secondary musculoskeletal problems. Various comorbidities that often accompany $\mathrm{CP}$ children negatively impact the quality of life of the child as well as family and community. [13]

Abnormalities or damage to $\mathrm{CP}$ can occur while in the womb (prenatal), during the birth process (perinatal), or after the birth process (postnatal). CP can cause disturbances (posture), motion control, disruption of muscle strength which is usually accompanied by neurological disorders in the form of paralysis, spasticity, basal ganglia disorders, cerebellum, and mental disorders. CP is not a stand-alone disease but a name given to variations of the syndrome of motor nerve damage that occurs secondary to lesions in brain development. Brain damage is permanent and cannot be cured but the impact of $\mathrm{CP}$ can be minimized. [14]

The severity and prognosis of $\mathrm{CP}$ depends on the clinical form and the presence of associated comorbidities (Minciu, 2012). Although there is no specific treatment for brain damage that causes motor dysfunction in $\mathrm{CP}$, clinical interventions that focus on reducing $\mathrm{CP}$ comorbidities can have a positive impact on the quality of life people with CP. [15]

Early intervention is an important thing to do in children with $\mathrm{CP}$, age 1-3 years is the best time to do because abnormal postural patterns are still not formed, but at this age many parents still consider only motor delays. Abnormal postural patterns and deformities in muscles and joints begin to emerge after 3 years, and it is at this time that parental awareness begins to increase about the need for intensive therapy even though this is not the best period to start therapy. [1]

Based on the results of the analysis and discussion in this study, the clinical implications that can be applied are the level of independence of basic functional functional activity in children with $\mathrm{CP}$ influenced by $\mathrm{CP}$ type. This can occur because each type of $\mathrm{CP}$ has different characteristics seen from the lesions experienced.

[6] K. Vitrikas, H. Dalton, and D. Breish, Copyright @2020, JURNAL KEBIDANAN, http://ejournal.poltekkes-smg.ac.id/ojs/index.php/jurkeb/index

\section{Conclusion}

Research on the type of $\mathrm{CP}$ based on the type of disability Obtained results in the form of: (1) type of CP which has the highest prevalence is spastic CP group consisting of spastic quadriplegia, spastic diplegia, and spastic hemiplegia, with the main symptoms of hypertonus in muscles caused by impaired cortical function, (2) based on the examination of basic functional abilities with GMFCS-ER, it is found that the majority of children with CP have a low or dependent level of independence, and (3) there is a perfectly positive relationship (+1) between cerebral palsy types and the degree of independence of basic functional functional activities in children based on correlation with Pearson product moment. Based on the results of the research that has been obtained, the researcher suggests conducting studies and or developing physiotherapy interventions or modalities that are adapted to the type of $\mathrm{CP}$ and disabilities they experience to improve the ability of functional activities in people with $\mathrm{CP}$ to be more independent.

\section{Acknowledgements}

Thank you to the community of cerebral palsy patients for their willingness to participate in the study. Thank you to the Poltekkes Kemenkes Surakarta who provided funding for this research.

\section{References}

[1] P. Morgan and J. L. McGinley, "Cerebral palsy," in Handbook of Clinical Neurology, 2018.

[2] S. Gulati and V. Sondhi, "Cerebral Palsy: An Overview," Indian Journal of Pediatrics. 2018.

[3] A. Colver, C. Fairhurst, and P. O. D. Pharoah, "Cerebral palsy," in The Lancet, 2014.

[4] M. Stavsky, O. Mor, S. A. Mastrolia, S. Greenbaum, N. G. Than, and O. Erez, "Cerebral palsy-trends in epidemiology and recent development in prenatal mechanisms of disease, treatment, and prevention," Frontiers in Pediatrics. 2017.

[5] H. Selina, W. Priambodo, and M. Sakundarno, "Gangguna Tidur Pada Anak Palsi Serebral," Medica Hosp. J. Clin. Med., 2013.

"Cerebral palsy: An overview," American 
Family Physician. 2020.

[7] S. Marret, C. Vanhulle, and A. Laquerriere, "Pathophysiology of cerebral palsy," Handb. Clin. Neurol., vol. 111, pp. 169-176, 2013.

[8] S. McIntyre, D. Taitz, J. Keogh, S. Goldsmith, N. Badawi, and E. Blair, "A systematic review of risk factors for cerebral palsy in children born at term in developed countries," Developmental Medicine and Child Neurology. 2013.

[9] D. Reddihough, "Cerebral palsy in childhood," Aust. Fam. Physician, 2011.

[10] L. K. Kenyon, "Gross Motor Function Measure (GMFM-66 and GMFM-88) Users' Manual," Phys. Occup. Ther. Pediatr., 2014.

[11] A. R. Harvey, "The Gross Motor Function Measure (GMFM)," Journal of
Physiotherapy. 2017.

[12] B. McDowell, "The gross motor function classification system - Expanded and revised," Dev. Med. Child Neurol., vol. 50, no. 10, p. 725, 2008.

[13] L. V. Gabis, N. M. Tsubary, O. Leon, A. Ashkenasi, and S. Shefer, "Assessment of abilities and comorbidities in children with cerebral palsy," J. Child Neurol., 2015.

[14] G. S. Liptak et al., "Providing a primary care medical home for children and youth with cerebral palsy," Pediatrics. 2011.

[15] D. W. Tessier, J. L. Hefner, and A. Newmeyer, "Factors Related to Psychosocial Quality of Life for Children with Cerebral Palsy," Int. J. Pediatr., 2014. 